\title{
ANALISIS FAKTOR-FAKTOR YANG MEMPENGARUHI PERMINTAAN SUSU SAPI PASTEURISASI DI KOPERASI PRODUKSI SUSU (KPS) BOGOR
}

\author{
Bella Yunita, Achmad Tjachja Nugraha* dan Acep Muhib
}

\begin{abstract}
ABSTRAK
Penelitian ini bertujuan untuk (1) mengetahui karakteristik konsumen yang mengkonsumsi susu pasteurisasi, (2) mengetahui faktor-faktor yang mempengaruhi tingkat permintaan susu pasteurisasi dan menganalisis pengaruh faktor-faktor ini pada permintaan susu pasteurisasi, dan (3) menganalisis elastisitas permintaan susu pasteurisasi. Penelitian ini dilakukan pada Koperasi Produksi Susu (KPS, Bogor Utara). Sebanyak 100 responden diwawancarai dengan menggunakan teknik purposive sampling. Analisis regresi berganda dan analisis elastisitas permintaan melalui program dari Microsoft Office Excel 2007 dan SPSS 21 digunakan untuk menganalisis data. Hasil penelitian menunjukkan bahwa pendapatan, jumlah anggota keluarga, usia, pendidikan, dan selera bersama-sama secara signifikan mempengaruhi permintaan susu pasteurisasi di KPS Bogor dengan tingkat kepercayaan 75\%. Hasil dari elastisitas jangka pendek menunjukkan bahwa kelima variabel tersebut inelastis.
\end{abstract}

Kata kunci: permintaan, susu, pasteurisasi, elastisitas

\section{ABSTRACT}

This study aims to (1) find out the characteristics of consumers who consume pasteurized milk, (2) determine the factors that affect the level of demand for pasteurized milk and analyze the influence of these factors on the demand for pasteurized milk, and (3) analyze the elasticity of demand for pasteurized milk. The research was conducted at the Dairy Cooperative Production (KPS, North Bogor). A total of 100 respondents were interviewed by using purposive sampling techniques. Multiple regression analysis and analysis of demand elasticity through programs of Microsoft Office Excel 2007 and SPSS 21 were employed to analyze the data. The results showed that incomes, number of family members, ages, educations, and tastes jointly significantly affect demand for pasteurized milk at KPS Bogor with confidence level of $75 \%$. The result from short-term elasticities showed that those five variables were inelastics.

Keywords: demand, milk, pasteurization, elasticity

\section{PENDAHULUAN}

Susu merupakan salah satu jenis bahan pangan dari sub sektor peternakan yang turut serta mempengaruhi pembangunan perekonomian nasional. Susu memiliki prospek yang baik untuk dikembangkan karena susu dibutuhkan oleh semua kalangan masyarakat.

Salah satu cara agar susu dapat disimpan lebih lama yaitu dengan cara pengolahan. Perkembangan teknologi yang semakin maju, saat ini sudah 
banyak usaha-usaha pengolahan susu segar menjadi berbagai bentuk olahan.

Proses pengolahan susu bertujuan untuk memperoleh susu yang beraneka ragam, berkualitas tinggi, berkadar gizi tinggi, tahan simpan, mempermudah pemasaran dan transportasi, sekaligus meningkatkan nilai tukar dan daya guna bahan mentahnya.Susu pasteurisasi merupakan produk olahan susu yang telah mengalami proses pemanasan selama $15-16$ detik pada suhu $71,7-75^{\circ} \mathrm{C}$ dengan alat plateheat exchanger.

Tabel 1. Rata-rata Konsumsi per kapita Rumah Tangga di Indonesia

\begin{tabular}{|c|c|}
\hline Tahun & Konsumsi(kg/kapita/tahun) \\
\hline 2009 & 1,91 \\
\hline 2010 & 2,03 \\
\hline 2011 & 2,07 \\
\hline 2012 & 1,63 \\
\hline 2013 & 2,04 \\
\hline
\end{tabular}

Sumber : SUSENAS, BPS 2014

Pada Tabel 1 dari tahun 2009-2013 mengalami peningkatan konsumsi susu pasteursiasi yaitu pada tahun 2009 konsumsi susu sebesar 1,91 dan pada tahun 2013 meningkat menjadi 2,04 kg per kapita per tahun.

Salah satu daerah yang ikut berkontribusi dalam peningkatan konsumsi susu pasteurisasi di Indonesia adalah kota Bogor. Bogor adalah dengan jumlah konsumsi susu pasteurisasi tebanyak kedua di daerah Jawa Barat. Hal tersebut dibuktikan dengan data pengeluaran rata-rata per kapita per bulan untuk konsumsi susu di wilayah Bogor tertera pada Tabel 2.

Tabel 2 menjelaskan bahwa konsumsi susu di wilayah Bogor meningkat mulai dari tahu 2009 hingga tahun 2013. Potensi susu pasteurisasi yang meningkat menjadi perhatian bagi para produsen untuk memenuhi permintaan tersebut. Salah satu produsen yang ikut berkontribusi dalam memenuhi permintaan susu pasteurisasi di daerah Bogor ialah Koperasi Produksi Susu (KPS).

Tabel 2. Rata-rata Pengeluaran Konsumsi Susu di Bogor Tahun 20092013

\begin{tabular}{|c|c|}
\hline Tahun & KonsumsiSusu \\
\hline 2009 & 23.010 \\
\hline 2010 & 26.874 \\
\hline 2011 & 15.581 \\
\hline 2012 & 26.541 \\
\hline 2013 & 27.036 \\
\hline
\end{tabular}

Sumber : BPS 2014

Koperasi Produksi Susu (KPS) Bogor merupakan koperasi penggerak bagi koperasi-koperasi sekunder yang ada di wilayah Bogor. Selain memproduksi dan mendistribusikan susu segar kepada para Industri Pengolahan Susu (IPS), KPS Bogor mengolah susu segar dalam bentuk susu pasteurisasi sebagai alternatif dalam meningkatkan harga beli susu dari peternak, sehingga tidak tergantung 100 persen pada Industri Pengolahan Susu (IPS).

Pada mulanya KPS memiliki 28 agen dalam memasarkan produknya, namun pada tahun 2012-2014 agen yang aktif hanya berkisar 23 agen. Grafik permintaan susu pasteurisasi KPS Bogor tertera pada Gambar 1.

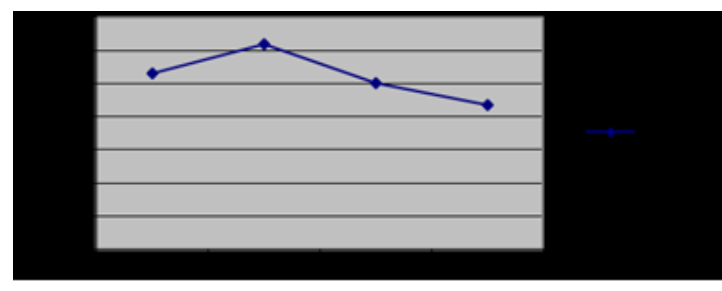

Gambar 1. Grafik Permintaan Susu Pasteurisasi KPS Bogor

Sumber : Data Primer KPS Bogor, 2014

Pada Gambar 1 dapat dilihat bahwa permintaan susu pasteurisasi mengalami penurunan permintaan pada tahun 2012 dan 2013. Pada tahun 2011 permintaan susu pasteurisasi mencapai 
123.751 liter dan pada tahun berikutnya menurun menjadi 102.536 liter. Oleh sebab itu, perlu dilakukan langkahlangkah untuk mengatasi permasalahan menurunnya permintaan konsumen terhadap susu pasteurisasi di KPS Bogor dengan memperhatikan faktor-faktor apa saja yang mempengaruhi permintaan konsumen tersebut. Berdasarkan pemaparan tersebut, maka peneliti melakukan penelitian mengenai "Analisis Faktor-Faktor Yang Mempengaruhi Permintaan Susu Pasteurisasi Di Koperasi Produksi Susu (KPS) Bogor".

\section{METODELOGI PENELITIAN}

\section{Lokasi dan Waktu Penelitian}

Penelitian dilaksanakan di

Koperasi Produksi Susu (KPS) Bogor, Provinsi Jawa Barat. KPS terletak di Jalan Baru Kedung Badak, Bogor Utara. Lokasi ini dipilih secara sengaja (purposive) dengan dasar pertimbangan bahwa KPS Bogor merupakan tempat pengumpulan susu sapi dari berbagai wilayah di Bogor yang menjual susu ke para konsumen (pabrik dan instansi) serta mengolah susu menjadi produk susu pasteurisasi. Penelitian dilakukan pada bulan Agustus-Desember

2014.

\section{Jenis dan Sumber Data}

Jenis data yang digunakan dalam penelitian ini terdiri dari dua jenis sumber data yaitu data primer dan data sekunder.

1. Data primer ialah data yang diperoleh dari sumber penelitian dan bersifat belum diolah.

2. Data sekunder ialah data yang di peroleh dari sumber yang menerbitkan dan bersifat siap pakai.

\section{Metode Pengumpulan Data}

Pengumpulan data yang dilakukan pada penelitian ini menggunakan tiga metode yaitu :

Observasi (Pengamatan Langsung)

Metode ini dilakukan dengan mengamati secara langsung objek penelitian di lapangan, sehingga memperoleh gambaran tentang KPS terutama di unit pasteurisasi yang dikelola.

Kuesioner

Kuesioner dilakukan dengan melakukan tanya jawab dengan menggunakan pertanyaan yang sudah di susun sebelumnya secara langsung kepada para konsumen.

Wawancara

Wawancara dilakukan dengan mencari tahu mengenai seluk beluk KPS Bogor terutama di bidang unit pasteurisasi, mulai dari sejarah struktur organisasi dan lainnya. Wawancara dilakukan kepada manajer dan pegawai KPS Bogor.

\section{Metode Penentuan dan Pengambilan Sampel}

Sampel merupakan bagian atau sejumlah cuplikan tertentu yang diambil dari suatu populasi dan diteliti secara rinci (Budiasih, 2010:21).

Berdasarkan teknik purposive sampling maka jumlah responden pada penelitian ini ialah 100 orang responden.

Teknik pengambilan sampel pada penelitian ini dilakukan selama 2 minggu dengan 5 hari kerja yaitu SeninJum'at dari pukul $10.00-16.00 \mathrm{WIB}$, dengan target responden berjumlah 10 orang per hari.

\section{Variabel dan Definisi Operasional}

Variabel yang digunakan dan definisi operasional variabel dalam penelitian ini ialah sebagai berikut : 
a. Variabel permintaan susu sapi pasteurisasi

Definisi variabel : jumlah atau banyaknya susu pasteurisasi yang dikonsumsi oleh konsumen pada rentang waktu 1 bulan dan dinyatakan dalam satuan liter.

b. Variabel pendapatan

Definisi variabel : pendapatan total konsumen dari berbagai sumber yang merupakan pendapatan per bulan. Pendapatan yang diteliti ialah pendapatan dalam bentuk rupiah.

c. Variabel jumlah anggota keluarga

Definisi variabel : banyaknya orang yang tinggal dalam satu rumah tersebut atas tanggungan kepala keluarga.

d. Variabel perbedaan usia

Definisi variabel : usia yang dimiliki oleh konsumen susu pasteurisasi

e. Variabel tingkat pendidikan

Definisi variabel : pendidikan terkakhir yang ditempuh oleh konsumen susu pasteurisasi.

f. Variabel Selera

Definisi variabel : keinginan konsumen dalam membeli susu pasteurisasi dibandingkan jenis susu olahan lain dan dibandingkan ditempat lain. Variabel ini diukur dengan menggunakan skala interval 1 hingga 5 .

\section{Metode Penelitian dan Analisis Data}

Data - data yang telah didapatkan berupa hasil dari kuesioner penelitian harus diolah dan dianalisis agar menghasilkan ouput atau kesimpulan yang sesuai dengan rumusan masalah pada penelitian. Metode analisis data yang digunakan dalam penelitian ini berupa metode analisis statsitik deskriptif (kualitatif) dan analisis kuantitatif.

Analisis Kuantitatif

Analisis kuantitatif digunakan untuk melihat seberapa besar faktorfaktor mempengerahui permintaan susu sapi pasteurisasi.
Regresi Berganda

Pengujian yang digunakan pada regresi berganda terdiri dari 3 pengujian yaitu keofisien determinasi (R2), pengujian parameter secara keseluruhan (uji F) dan pengujian parameter regresi secara tunggal (uji t).

Analisis Elastisitas Permintaan

Analisis elastisitas digunakan untuk mengetahui persentase kenaikan atau penurunan jumlah permintaan susu pasteurisasi, jika terjadi perubahan harga dan pendapatan. Rumus mencari elastisitas permintaan ialah sebagai berikut :

$$
E d=\frac{Q_{1}-Q}{Q} \quad: \frac{P_{1}-P}{P}
$$

Berdasarkan rumus tersebut akan didapatkan beberapa kriteria elastisitas permintaan yaitu :

1. In elastisitas sempurna jika $E=0$

2. In elastis jika $\mathrm{E}<1$

3. Elastis uniter jika $E=1$

4. Elastis jika $\mathrm{E}>1$

5. Elastis sempurna jika $E=\infty$

\section{Hipotesis Awal}

Berdasarkan persamaan regresi mengenai faktor- faktor yang mempengaruhi permintaan susu sapi segar, maka didapatkan hipotesis sebagai berikut:

1. Beberapa faktor - faktor permintaan tersebut diantaranya terdapat faktor yang berpengaruh secara nyata dan kurang berpengaruh (tidak berpengaruh). Faktor yang diperkirakan berpengaruh nyata ialah pendapatan, jumlah anggota keluarga, selera. Faktor yang dirasa kurang berpengaruh (tidak berpengaruh) ialah usia dan pendidikan. 2. Terdapat hubungan (positif/negatif) dan signifikan antara pendapatan 
konsumen (X2) dengan permintaan susu pasteurisasi (Y) di KPS Bogor.

3. Terdapat hubungan (positif/negatif) dan signifikan antara jumlah anggota keluarga konsumen (X3) dengan permintaan susu pasteurisasi (Y) di KPS Bogor.

4. Terdapat hubungan (positif/negatif) dan signifikan antara pendidikan konsumen (X4) dengan permintaan susu pasteurisasi (Y) di KPS Bogor.

5. Terdapat hubungan (positif/negatif) dan signifikan antara usia konsumen

(X5) dengan permintaan susu pasteurisasi (Y) di KPS Bogor.

6. Terdapat hubungan (positif/negatif) dan signifikan antara selera konsumen (X6) dengan permintaan susu pasteurisasi (Y) di KPS Bogor.

7. Susu sapi pasteurisasi merupakan salah satu bahan pangan yang biasa dikonsumsi oleh sebagian masyarakat. Susu sapi pasteurisasi ini diperkirakan memiliki elastisitas kurang dari satu $(\mathrm{E}<1)$ artinya perubahan harga lebih besar dibandingkan perubahan jumlah permintaan yang sama. Hal seperti itu dinamakan inelastis (tidak elastis).

\section{HASIL DAN PEMBAHASAN}

\section{Karakteristik Konsumen}

Responden dalam penelitian ini ialah para konsumen yang membeli dan mengkonsumsi produk susu pasteurisasi yang berasal dari KPS (Koperasi Produksi Susu) Bogor yang berjumlah 100 orang berdasarkan rumus RAO.

Faktor-Faktor Yang Mempengaruhi Permintaan Susu Pasteurisasi KPS Bogor

Hasil regresi faktor-faktor yang mempengaruhi permintaan susu pasteurisasi pada konsumen konsumen KPS Bogor

\begin{tabular}{|l|l|l|}
\hline No & $\begin{array}{l}\text { Faktor -Faktor } \\
\text { YangMempengaruhi Permintaan }\end{array}$ & $\begin{array}{l}\text { Koefisien } \\
\text { Regresi }\end{array}$ \\
\hline 1 & Pendapatan $\left(\mathrm{X}_{1}\right)$ & $-1,862$ \\
\hline 2 & Jumlah AnggotaKeluarga $\left(\mathrm{X}_{2}\right)$ & 0,381 \\
\hline 3 & Pendidikan $\left(\mathrm{X}_{3}\right)$ & 0,166 \\
\hline 4 & Usia(X4) & 0,056 \\
\hline 5 & Selera $\left(\mathrm{X}_{5}\right)$ & 0,827 \\
\hline & Konstanta & 8,681 \\
\hline
\end{tabular}

Sumber : Data Primer (Hasil Olahan SPSS 21)

Berdasarkan perhitungan pada Tabel 9, persamaan regresi berganda yang didapat untuk faktor-faktor yang mempengaruhi permintaan susu pasteurisasi di KPS Bogor ialah sebagai berikut :

$\mathrm{Y}=8,681-1,862 \mathrm{X}_{1}+0,381 \mathrm{X}_{2}+0,166 \mathrm{X}_{3}$ $+0,056 \mathrm{X}_{4}+0,827 \mathrm{X}_{5}$

Uji Determinasi (R2)

Tabel Hasil Pengujian Determinasi (R2)

\begin{tabular}{|l|l|l|}
\hline No & Keterangan & Nilai \\
\hline 1 & $\mathrm{R}$ & 0,857 \\
\hline 2 & $\mathrm{R}^{2}$ & 0,781 \\
\hline 3 & $\mathrm{R}^{2}$ yangdisesuaikan & 0,503 \\
\hline
\end{tabular}

Sumber : Data Primer (Hasil Olahan SPSS 21)

Besarnya hubungan antara variabel bebas dan variabel terikat dapat diketahui dengan melihat angka koefisien korelasi (R). Pada Tabel 10 nilai $\mathrm{R}$ yang didapatkan pada penelitian ini adalah 85,7 \%. Hasil tersebut memiliki pengertian bahwa hubungan variabel pendapatan (X1), jumlah anggota keluarga (X2), pendidikan (X3), usia (X4) dan selera (X5) dengan permintaan susu pasteurisasi adalah kuat. 
Pengujian Paramater Secara Tabel Hasil Uji F

Keseluruhan (Uji F)

\begin{tabular}{|c|l|l|l|l|l|l|l|}
\hline \multicolumn{2}{|l|}{ Model } & $\begin{array}{l}\text { Sum of } \\
\text { Squares }\end{array}$ & Df & $\begin{array}{l}\text { Mean } \\
\text { Square }\end{array}$ & Fhitung & Ftabel & Sig. \\
\hline 1 & Regresi & 95.257 & 5 & 19.051 & 1,589 & 1,350 & $171^{\mathrm{a}}$ \\
\cline { 2 - 8 } & Sisa & 1126.936 & 94 & 11.989 & & & \\
\cline { 2 - 8 } & Total & 222.194 & 99 & & & & \\
\hline
\end{tabular}

Hasil perhitungan uji F pada Tabel 19 diperoleh Fhitung ialah 1,589 lebih besar dibandingkan dengan Ftabel yaitu 1,589 dengan tingkat kepercayaan $75 \%$ dan nilai signifikan yang didapat ialah 0,171 lebih kecil dari $\square(0,25)$.

Pengujian Parameter Secara Tunggal (Uji t)

Uji t digunakan untuk melihat masing-masing faktor yang memiliki pengaruh terhadap permintaan serta faktor yang tidak berpengaruh pada permintaan susu pasteurisasi. Hasil yang di dapatkan uji t dapat dilihat pada Tabel 12.

\begin{tabular}{|l|l|l|l|}
\hline $\begin{array}{l}\text { Faktor- Faktor } \\
\text { Yang } \\
\text { Mempengaruhi } \\
\text { Permintaan }\end{array}$ & Ujit & $\begin{array}{l}\text { Signifika } \\
\mathrm{n}\end{array}$ & Ttabel \\
\hline Pendapatan (X1) & $-0,990$ & 0,325 & $0,677^{*}$ \\
\hline $\begin{array}{l}\text { Jumlah anggota } \\
\text { keluarga(X2) }\end{array}$ & 1,175 & 0,243 & \\
\hline Pendidikan (X3) & 1,134 & 0,260 & \\
\hline Usia(X4) & 1,072 & 0,287 & \\
\hline Selera (X5) & 1,090 & 0,278 & \\
\hline
\end{tabular}

Sumber : Data Primer (Diolah)

Keterangan: *tingkat kepercayaan 7 
Elastisitas Permintaan

Tabel 16. Elastisitas Permintaan Susu Pasteurisasi KPS Bogor

\begin{tabular}{|l|c|l|}
\hline \multicolumn{1}{|c|}{ Variabel } & NilaiElastisitas & Keterangan \\
\hline Pendapatan $\left(\mathrm{X}_{1}\right)$ & $-0,498$ & Inelastis \\
\hline $\begin{array}{l}\text { Jumlah anggota } \\
\text { keluarga }\left(\mathrm{X}_{2}\right)\end{array}$ & 0,349 & Inelastis \\
\hline Pendidikan $\left(\mathrm{X}_{3}\right)$ & 0,470 & Inelastis \\
\hline Usia $\left(\mathrm{X}_{4}\right)$ & 0,328 & Inelastis \\
\hline Selera $\left(\mathrm{X}_{5}\right)$ & 0,615 & Inelastis \\
\hline
\end{tabular}

Sumber : Data Primer (Diolah)

Hasil penelitian mengenai elastisitas pemintaan yang tertera pada Tabel 16 ialah ke lima variabel yaitu pendapatan, jumlah anggota keluarga, pendidikan, usia dan selera memiliki nilai elastisitas kurang dari 1 yang artinya bersifat tidak elastis. Berikut merupakan hasil perhitungan elastisitas permintaan dari masing- masing variabel bebas pada penelitian :

Elastisitas Pendapatan

Elastisitas pendapatan menunjukkan besarnya perubahan permintaan susu pasteurisasi sebagai respon dari perubahan pendapatan konsumen. Pada Tabel 16 didapatkan bahwa hasil variabel pendapatan memiliki sifat inelastis dimana elastisitas yang didapat memiliki nilai kurang dari 1 yaitu $-0,498 \quad(-0,498<1)$.

Elastisitas Jumlah Anggota Keluarga Jumlah anggota keluarga memiliki sifat inelastis yaitu kurang dari $1(0,349<1)$. Jumlah anggota keluarga bersifat inelastis yang artinya peningkatan jumlah anggota keluarga akan memberikan respon yang lebih kecil terhadap peningkatan jumlah permintaan susu pasteurisasi di KPS Bogor.

\section{Elastisitas Pendidikan}

Hasil pengujian elastisitas permintaan pada Tabel 16 diketahui bahwa pendidikan bernilai 0,470 yaitu bersifat inelastis dikarenakan kurang dari 1. Nilai elastisitas pendidikan bersifat inelastis yang artinya persentase perubahan jumlah susu pasteurisasi yang di minta lebih kecil dibandingkan persentase perubahan tingkat pendidikan konsumen.

Elastisitas Usia

Variabel usia berdasarkan hasil pengujian elastisitas permintaan bernilai 0,328 yang berarti memiliki sifat inelastis.. Nilai elastisitas usia bersifat inelastis artinya perubahan peningkatan usia akan memberikan respon yang lebih kecil terhadap peningkatan jumlah permintaan akan susu pasteurisasi. Elastisitas usia bersifat inelastis terjadi karena walaupun usia konsumen meningkat tiap tahunnya, namun tidak semua konsumen mengkonsumsi susu pasteurisasi.

\section{Elastisitas Selera}

Pada variabel selera memiliki nilai elastisitas kurang dari $1 \quad(0,615<1)$ yang berarti bersifat inelastis. Persentase perubahan jumlah susu pasteurisasi yang di minta lebih kecil dibandingkan persentase perubahan selera konsumen. Elastisitas selera bersifat inelastis dikarenakan walaupun terjadi kenaikan konsumsi pada susu cair, tetapi masih banyak konsumen yang mengkonsumsi susu olahan seperti susu bubuk maupun susu kental manis.

\section{KESIMPULAN}

1. Karakteristik konsumen susu pasteurisasi di KPS Bogor ialah sebagian besar seorang wanita. Konsumen terbanyak yang biasa membeli susu pasteurisasi tersebut bekerja sebagai pegawai negeri sipil dengan usia rentang 26-35 tahun. Pendidikan terbanyak konsumen ialah Strata 1 (S1).

2. Faktor-faktor yang mempengaruhi permintaan pasteurisasi pada penelitian ini terdiri dari lima variabel, yaitu pendapatan keluarga, jumlah anggota keluarga, pendidikan, 
usia dan selera. Hasil uji t pada lima variabel bebas pada penelitian ini berpengaruh secara nyata terhadap permintaan susu pasteurisasi dengan tingkat kepercayaan $75 \%$ dengan syarat yaitu thitung $>$ ttabel. Hasil uji $F$ pada penelitian didapatkan bahwa semua variabel bebas secara

bersama sama berpengaruh terhadap permintaan susu pasteurisasi, dan hasil uji determinasi didapatkan bahwa $78,1 \%$ variabel bebas pada penelitian dapat menggambarkan pengaruh terhadap permintaan susu pasteurisasi.

3. Hasil perhitungan elastisitas permintaan susu pasteurisasi didapatkan bahwa ke lima variabel, pendapatan, jumlah anggota keluarga, pendidikan,usia dan selera memiliki nilai kurang dari 1 yang memiliki arti bahwa bersifat inelastis. Hal tersebut menandakan persentase perubahan jumlah permintaan susu pasteurisasi yang diminta lebih kecil dibandingkan persentase perubahan variabel permintaan.

\section{DAFTAR PUSTAKA}

Daryanto, Arief. Peningkatan Daya Saing Industri Peternakan. (Jakarta : PenerbitTrobos, 2007).

Effendi, Sofiyan dan Tukiran. Metode Penelitian Survei. (Jakarta : Penerbit LP3ES, 2012).

Eniza, S. Teknologi Pengolahan Susu dan Hasil Ikutan Ternak. [Jurnal Sainteks 9(2) : 77-8], 2004.

Farid, Miftah dan Heny Sukesi. Pengembangan Susu Segar Dalam Negeri Untuk Pemenuhan Kebutuhan Susu Nasional [Jurnal].
(Buletin Ilmiah Litbang Perdagangan Vol 5 (2), 2011).

Gilarso, T. Pengantar Ilmu Ekonomi Mikro. (Yogyakarta : Penerbit Konsius, 2003).

Ghazali, I. Aplikasi Analisis Multivariate Dengan Program SPSS. (Semarang : Badan Penerbit Universitas Diponegoro, 2002).

Haromain, Iman. Faktor- Faktor Yang Mempengaruhi Permintaan Daging Sapi Di Indonesia Pada Tahun 20002009 [Skripsi]. (Jakarta : Fakultas Sains dan Teknologi UIN Syarif Hidayatullah, 2010).

Hari dan Nova, Budi Hartono. Analisis Faktor - Faktor Yang Mempengaruhi Konsumen Dalam Membeli Produk Susu Pasteurisasi Kabupaten Kudus [Jurnal]. (Buletin Peternakan Vol. 34(2): 123-130, 2010).

Haryadi, Pedri. Analisis Faktor - Faktor Yang Mempengaruhi Permintaan Daging Ayam Di Desa Cogreg, Kecamatan Parung, Kabupaten Bogor, Propinsi Jawa Barat [Skripsi]. (Jakarta : Fakultas Sains dan Teknologi, 2013)

Lipsey, Richard G, Peter O. Steiner dan Douglas D. Purvis. Pengantar Mikroekonomi. Edisi Kedelapan. (Jakarta : Penerbit Erlangga, 1997). Lukman. Pengantar Teori Mikro Ekonomi. (Jakarta : Penrbit UIN Jakarta Press, 2007).

Manurung, Mandala dan Prathama Rahadja. Teori Ekonomi Mikro. Edisi Ketiga. (Jakarta : Lembaga Penerbit 
Fakultas Ekonomi Universitas Indonesia, 2006).

Masyhuri. Ekonomi Mikro. (Malang : UIN Malang Press, 2007).

Moh Nazir. Metode Penelitian. (Bogor : Penerbit Ghalia Indah, 2011).

Nachrowi, Djalal dan Hardius Usman. Penggunaan Teknik Ekonometrik. (Jakarta: Penerbit PT Raja Grafindo Persada, 2008).

Nasution, Nurayla Arnas. Analisis Faktor-Faktor Yang Mempengaruhi Permintaan Rumah Tangga Terhadap Sayuran Organik Di Kota Bogor, Jawa Barat [Skripsi]. (Bogor : Fakultas Ekonomi dan Manajemen Institut Pertanian Bogor, 2009)

Ruslan, Rosady. Metode Penelitian Public Relations dan Komunikasi. (Jakarta ..Penerbit PT Raja Grafindo Persada, 2008).

Santosa, Singgih. Statistik Parametik. (Jakarta: PT Elex Media Komputindo, 2010).

Setiawan, Kusrini dan Dwi Endah. Ekonometrika. (Yogyakarta : Penerbit Andi, 2010)

Sugiyono. Metode Penelitian Kuantitatif Kualitatif dan R\&D. (Bandung: Penerbit Alfabeta, 2013).

Sukirno, Sadono. Mikroekonomi Teori Pengantar. Edisi Ketiga. (Jakarta : Penerbit Rajawali Press, 2012).

Suryani, Tatik. Perilaku Konsumen: Implikasi Pada Strategi Pemasaran.
Edisi Pertama. (Yogyakarta: Penerbit Graha Ilmu, 2008).

Sunyoto, Danang. Dasar-dasar Manajemen Pemasaran. (Yogyakarta : Ceneter For Academic Publishing Center, 2012)

Solihah, Elis. Analisis Faktor-Faktor Yang Mempengaruhi Permintaan Konsumen Daging Ayam Broiler Di Bel Mart Cinere, Depok [Skripsi]. (Jakarta : Fakultas Sains dan Teknologi UIN Syarif Hidayatullah, 2014)

Ulfa, Andhieka. Analisis Faktor- Faktor Yang Mempengaruhi Permintaan Tempe Di Desa Jombang, Kecamatan Ciputat, Kota Tangerang Selatan, Propinsi Banten [Skripsi]. (Jakarta : Fakultas Sains dan Teknologi UIN Syarif Hidayatullah, 2011)

Uyanto, Stanislaus S. Pedoman Analisis Data dengan SPSS. Edisi 3 ( Yogyakarta: Graha Ilmu,2013)

Wijaya, Tony. Metodologi Penelitian Ekonomi dan Bisnis Teori dan Praktik. (Yogyakarta: Graha Ilmu, 2013)

\section{* Alamat Korespondensi: tjachja.nugraha@uinjkt.ac.id}

